\section{Commentary: Tasting individual ingredients of meso soup: Can 'omics bring out the flavor?}

\author{
Harvey I. Pass, MD
}

It's funny how things you say in the past come around to haunt you. In 2002, I wrote a commentary about the state of the art of surgery for mesothelioma, lamenting about the slow pace of clinical/surgical breakthroughs for the disease. ${ }^{1}$ I did know, however, that the revolution in studying the genomics of the disease had already started in the Northeast, led by Bueno and Sugarbaker, ${ }^{2}$ and it was only a matter of time (and money) before large, relevant, well-annotated series of patients with pleural mesothelioma would be "clustered" according molecular, rather than histologic, phenotype..$^{3-5}$

It's 18 years later, and maybe the clues to what makes the difference in how patients do with pleural mesothelioma point to understanding basic pathways. This has sort of been the low-hanging fruit with this disease: these patients don't do very well with few exceptions; there isn't great therapy; surgery, although not defined by standard operating procedures from one place to the other, can help us figure out what's going on because we can use the evolution of next-generation sequencing and transcriptomics to define prognostic clusters. Essentially, despite the genomic revolution, the simplest of principles seems to hold: sarcomatoid does lousy and epithelial does better $^{6}$; easy, so if you mix sarcomatoid and epithelial, you get biphasic, and its prognosis is variable. It's not that easy: if you mix red and green, you get yellow; if you mix epithelial and sarcomatoid, you don't get yellow, but you get a rainbow of possible outcomes.

From the Division of Thoracic Surgery, Department of Cardiothoracic Surgery, NYU Langone Health, New York, NY.

Disclosures: The author reported no conflicts of interest.

The Journal policy requires editors and reviewers to disclose conflicts of interest and to decline handling or reviewing manuscripts for which they may have a conflict of interest. The editors and reviewers of this article have no conflicts of interest.

Received for publication March 26, 2020; accepted for publication March 26, 2020; available ahead of print April 18, 2020.

Address for reprints: Harvey I. Pass, MD, Department of Cardiothoracic Surgery/ General Thoracic Surgery, NYU Langone Medical Center, 530 First Ave, 9V, New York, NY 10016 (E-mail: Harvey.pass@nyumc.org).

J Thorac Cardiovasc Surg 2020;160:1084-5 0022-5223/ $\$ 36.00$

Copyright $₫ 2020$ Published by Elsevier Inc. on behalf of The American Association for Thoracic Surgery

https://doi.org/10.1016/j.jtcvs.2020.03.149

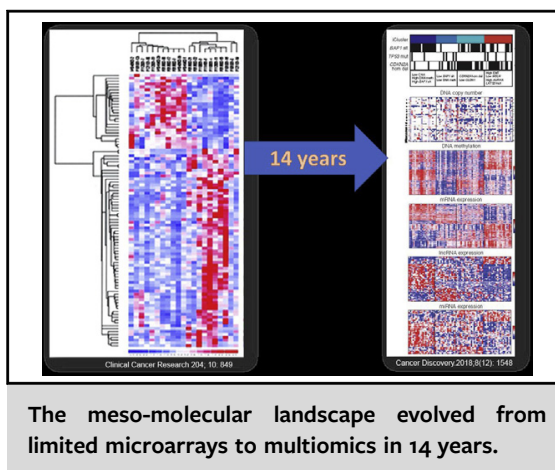

CENTRAL MESSAGE

An evolution of molecular biology techniques is broadening our understanding of mesothelioma. Molecular phenotyping will guide diagnosis, prognosis, as well as prediction of therapeutic response.

The molecular revolution, as so aptly defined by Severson and colleagues, ${ }^{7}$ tries not to "get caught up in the details" (individual genes); it tries to take bundles of genes and see how they work or don't work together to create pathways, and these pathways become the rainbow of possibilities, blending and interacting with each other to determine an intermediate endpoint in an individual patient. Generalities can be made, however, for groups or "clusters" of patients that seem to be governed by the same pathways. These generalities are the fruits of the terabytes of data that have been published as illustrated by the timeline in the "Age of Omics," but the beauty of this exercise becomes relevant when you start to concentrate on those issues that could explain the variety of outcomes for these patients.

Severson and colleagues ${ }^{7}$ give a powerful discussion of at least one of these "rainbow of possibilities" that could be the mother of all pathways for prognosis, which is known as epithelial mesenchymal transition (EMT). The beauty of this discussion is that 2 completely independent laboratories, working with completely different genomic algorithms, have seemed to come to the same conclusion. The rainbow of differences between epithelial and sarcomatoid outcomes, seen in the biphasic histology, is defined by genes, which can change cells from Jekyll to Hyde, ie, become much more invasive with the ability to 
cross boundaries, and metastasize. High EMT with these types of genes is more like sarcomatoid; low EMT is more like epithelial; the revelation, however, is the gradient of EMT, as alluded to by the variation in the ratio of gene levels associated with EMT from the work of Bueno and colleagues (claudin and vimentin). The "ah-ha!" moment comes when Blum and colleagues ${ }^{5}$ also devise an epithelial or sarcomatoid score from 150 genes derived from a methodology that essentially "orders" or deconvolutes the molecular tumor heterogeneity of the samples, and sure enough the epithelial score is associated with the claudins as detailed by the group of Bueno and colleagues.

So it's that easy, huh? No, it's not. Sure, we can subdivide patients into categories of high risk for failure or low risk for failure using a variety of the tools given to use by the molecular revolution, including claudin/vimentin ratios and epithelial/sarcomatoid deconvolution schemes, and they may even correlate with each other. However, the issues that remain include the margin of error in these predictions because they may not have the sensitivity and specificity for individual personalized prognostication. Moreover, mesothelioma is polyclonal, ${ }^{8,9}$ and if we were to base our predictions solely on a single biopsy, how do we know what the molecular phenotype is in other areas of the tumor? Of course I am nit-picking, and you don't have to convince me how important the evolution of 'omics will be not only in prognosticating patients, but in finding better markers for therapy, including those for immunotherapy of mesothelioma with or without chemotherapy. ${ }^{10}$ There is where the rubber meets the road ....accurate prediction of therapy using the mesothelioma 'omics revolution. Better yet is the accelerating pace of discovery at a number of international 'omics laboratories for improved strategies for mesothelioma. ${ }^{11-13}$
Oh well...a continuing and evolving explosion of molecular insight in pleural mesothelioma.

Who knew?

\section{References}

1. Pass HI. Pleural mesothelioma in 2002: going somewhere very slowly. J Thorac Cardiovasc Surg. 2002;124:1074-7.

2. Gordon GJ, Jensen RV, Hsiao LL, Gullans SR, Blumenstock JE, Richards WG, et al. Using gene expression ratios to predict outcome among patients with mesothelioma. J Natl Cancer Inst. 2003:95:598-605.

3. Bueno R, Stawiski EW, Goldstein LD, Durinck S, De Rienzo A, Modrusan Z, et al. Comprehensive genomic analysis of malignant pleural mesothelioma identifies recurrent mutations, gene fusions and splicing alterations. Nat Genet. 2016; 48:407-16.

4. Hmeljak J, Sanchez-Vega F, Hoadley KA, Shih J, Stewart C, Heiman D, et al. Integrative molecular characterization of malignant pleural mesothelioma. Cancer Discov. 2018;8:1548-65.

5. Blum Y, Meiller C, Quetel L, Elarouci N, Ayadi M, Tashtanbaeva D, et al. Dissecting heterogeneity in malignant pleural mesothelioma through histo-molecular gradients for clinical applications. Nat Commun. 2019;10: 1333.

6. Vigneswaran WT, Kircheva DY, Ananthanarayanan V, Watson S, Arif Q, Celauro AD, et al. Amount of epithelioid differentiation is a predictor of survival in malignant pleural mesothelioma. Ann Thorac Surg. 2017;103:962-6.

7. Severson DT, De Rienzo A, Bueno R. Mesothelioma in the age of "omics": before and after the TCGA. J Thorac Cardiovasc Surg. 2020;160:1078-83.e2.

8. Comertpay S, Pastorino S, Tanji M, Mezzapelle R, Strianese O, Napolitano A, et al. Evaluation of clonal origin of malignant mesothelioma. J Transl Med. 2014; $12: 301$.

9. Kiyotani K, Park JH, Inoue H, Husain A, Olugbile S, Zewde M, et al. Integrated analysis of somatic mutations and immune microenvironment in malignant pleural mesothelioma. Oncoimmunology. 2017;6:e1278330.

10. Nowak AK, Forde PM. Immunotherapy trials in mesothelioma-promising results, but don't stop here. Nat Rev Clin Oncol. 2019;16:726-8.

11. Yap TA, Aerts JG, Popat S, Fennell DA. Novel insights into mesothelioma biology and implications for therapy. Nat Rev Cancer. 2017;17: 475-88.

12. McCambridge AJ, Napolitano A, Mansfield AS, Fennell DA, Sekido Y, Nowak AK, et al. Progress in the management of malignant pleural mesothelioma in 2017. J Thorac Oncol. 2018;13:606-23.

13. Nicholson AG, Sauter JL, Nowak AK, Kindler HL, Gill RR, Remy-Jardin M, et al. EURACAN/IASLC proposals for updating the histologic classification of pleural mesothelioma: towards a more multidisciplinary approach. J Thorac Oncol. 2020;15:29-49. 